\title{
POLÍTICAS DE CONSTRUÇÃO DE TERRITÓRIO LOCAL DE ATUAÇÃO PARA A BIBLIOTECA PÚBLICA
}

\author{
Maria Cleide Rodrigues Bernardino*
}

RESUMO As bibliotecas públicas assumem desafios de grandes dimensões na sociedade, principalmente pelo desenvolvimento dos sistemas de informação e responsabilidades perante a sociedade da informação. A construção social de um território local para as bibliotecas públicas é uma interpretação da expressividade do cenário de identidades local e regional da comunidade usuária em prol da coletividade. $O$ objetivo desse trabalho é refletir sobre a atuação do Sistema Nacional de Bibliotecas Públicas - SNBP/RJ para a construção social de um território local de desenvolvimento para a informação e o conhecimento a partir das bibliotecas públicas. A pesquisa exploratória permite uma visão geral do fato e a análise qualitativa contribui para a elaboração de construtos sociais norteadores das políticas para as bibliotecas públicas. Ao elencar o raio de atuação e os aspectos de gestão de políticas públicas no território brasileiro, são apontados como resultados um mapeamento local e global da atuação das bibliotecas públicas do SNBP/RJ, contribuindo para a projeção sociopolítica das bibliotecas públicas e de sua inegável contribuição para $\bigcirc$ desenvolvimento local. Entendemos que a função da biblioteca pública de garantir o acesso a informação em qualquer suporte ou formato sendo um aspecto fundamental para o desenvolvimento da cultura e da educação e tem caráter democrático e social. Por fim, apresentamos as contribuições da biblioteca pública para a promoção humana a partir do reconhecimento das realidades locais, integrando culturas e promovendo o empoderamento das pessoas e grupos, incentivando assim, o desenvolvimento econômico e social da comunidade.

Palavras-chave: Biblioteca Pública. Território Local. Desenvolvimento Social. Sociedade da Informação. Biblioteca.

\footnotetext{
* Doutora em Ciência da Informação pela Universidade de Brasília, Brasil. Professora do Curso de Biblioteconomia e do Programa de Pós-Graduação em Biblioteconomia, da Universidade Federal do Cariri, Brasil. Líder do Grupo de Pesquisa Biblioteca, Informação e Sociedade.

E-mail: cleide.rodrigues@ufca.edu.br.
}

\section{INTRODUÇÃO}

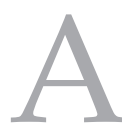

S bibliotecas públicas do século XXI enfrentam novos desafios de grandes dimensões na sociedade moderna. Isto se deve principalmente aos avanços tecnológicos e pelo valor social da informação na vida da sociedade.

As bibliotecas públicas são espaços socioculturais que desempenham para a comunidade em que atuam serviços informacionais abrigados em múltiplos suportes. Fala-se muito que com o passar dos anos as bibliotecas, em especial a biblioteca pública, deixou de ser um simples depósito de livros para se transformar em um espaço democrático de informação e cultura. Entretanto, não podemos esquecer que, em consonância com Díaz (2006), a biblioteca pública atual segue com poucas transformações do modelo herdado dos séculos 
XIX e XX. Apesar das inúmeras transformações que a informação e seus suportes passaram ao longo dos séculos, a biblioteca pública caminha a passos lentos e perde espaço de atuação perante a sua comunidade usuária. E não estamos falando de algo pontual, que acontece, sobretudo, no Brasil, mas em uma constância, que infelizmente ainda é a principal responsável pela imagem das bibliotecas públicas.

Pinheiro (2009) afirma que a biblioteca pública é um serviço público tradicional conhecido pelo morador de qualquer cidade, assim como a delegacia, a escola, o hospital etc, entretanto, isto não significa que o seu papel seja claro ou imutável para esta comunidade. É possível afirmarmos que a comunidade consegue viver sem a escola, o hospital ou a delegacia? E sem a biblioteca pública? Qual a real significância dessa instituição para a sociedade?

A biblioteca pública precisa construir um território local de atuação para esta sociedade. Necessita se fazer presente e atuante. Reconhecida. Necessária. Para isto é importante a reflexão de seu papel na sociedade, reconhecer sua identidade local, sua função para o desenvolvimento da cultura e da cidadania. Por ser um serviço público, "deveria reconhecer sua potencialidade para a transformação das estruturas sociais" (DÍAZ, 2006, p. 23).

Betancur (2007) afirma que as bibliotecas públicas são atores dinamizadores da construção social do território por sua tripla função de proporcionar a formação de uma sociedade leitora; garantir o acesso a informação local, regional, nacional e internacional em todo e qualquer suporte e formato; e divulgar e fomentar o desenvolvimento cultural.

Com esse pensamento pretendemos refletir sobre a atuação do Sistema Nacional de Bibliotecas Públicas (SNBP/RJ) para a construção social de um território local de desenvolvimento para a informação e o conhecimento a partir das bibliotecas públicas.

A investigação é desenhada por uma pesquisa exploratória que, de acordo com Gil (1999), permite uma visão geral do fato observado com delineamento qualitativo, o que contribuirá para a elaboração dos construtos sociais norteadores das políticas públicas que se constituem em elemento fundamental para a construção de um território de atuação social para bibliotecas públicas.

A pesquisa objetiva ainda elencar o raio de atuação e os aspectos de gestão das políticas públicas no território brasileiro, apontados como resultados em mapeamento local e global da atuação das bibliotecas públicas do SNBP/RJ, contribuindo para a projeção sociopolítica das bibliotecas públicas e de sua contribuição para o desenvolvimento local.

Por fim, apresentamos as contribuições da biblioteca pública para a promoção humana a partir do reconhecimento das realidades brasileiras locais, integrando culturas e promovendo o empoderamento das pessoas e grupos, incentivando assim, o desenvolvimento econômico e social da comunidade.

\section{TERRITÓRIO LOCAL DE ATUAÇÃO PARA AS BIBLIOTECAS PÚBLICAS}

O panorama de atuação das bibliotecas públicas na sociedade da informação impulsiona a geração e disseminação do conhecimento e configura novos modelos desejáveis para a comunidade usuária. Para esta reflexão vale ressaltar o conceito de biblioteca pública na sociedade moderna, que conforme falamos anteriormente, apesar das inúmeras transformações que passou a sociedade ao longo dos tempos, resiste em se basear em modelos de séculos passados. O grupo de estudos em bibliotecas públicas do Centro de Investigações em Ciência da Informação da Escola Interamericana de Biblioteconomia da Universidade de Antioquia, Colômbia, fez uma revisão a cerca do conceito de biblioteca pública na América Latina.

Seus estudos encaminharam a um entendimento que a construção de um novo conceito de biblioteca pública deverá englobar a compreensão da missão social e cultural de uma forma que permita visualizar sua articulação com a realidade social, sem esquecer de contemplar componentes de sua atuação como o entorno, os sujeitos e o contexto local (JARAMILLO; RIOS, 2005). 
Figura 1: Mapa conceitual da biblioteca pública

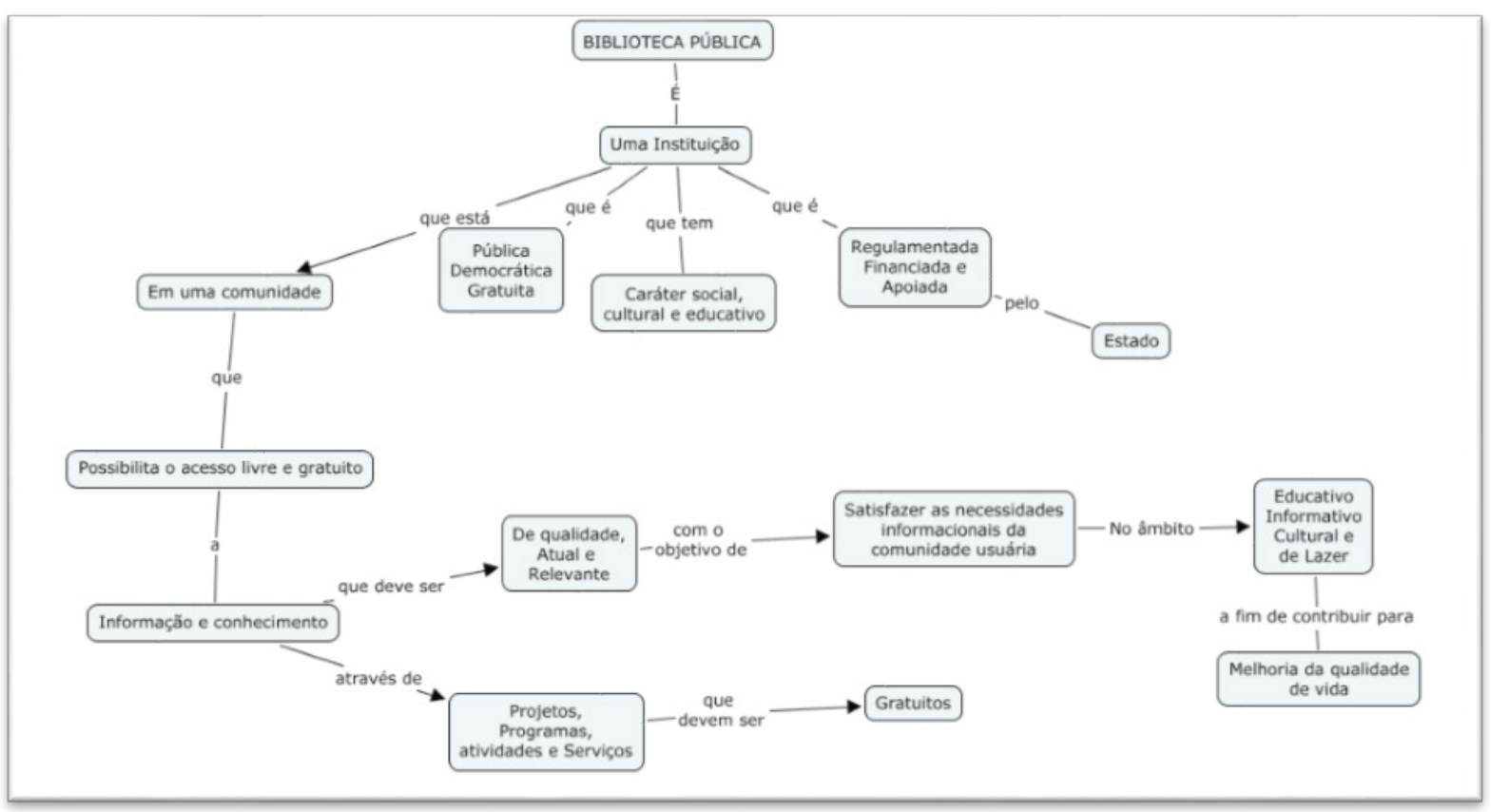

Fonte: A autora.

Pinheiro (2009, p. 27) afirma que a biblioteca pública é um sistema democrático de acesso à informação e à leitura e que, portanto, deve "respeitar a diversidade de interesses e abrir possibilidades de integração do indivíduo no campo decisório desse sistema". Para abrir possibilidades de integração do indivíduo por sua vez, é preciso um conhecimento íntimo do que Betancur (2007) chama de tripla função da biblioteca pública que centra-se na formação de uma sociedade leitora, no acesso a informação e no fomento ao desenvolvimento cultural. Neste sentido abrir possibilidades de integração é o primeiro passo para construir um território local de atuação para a biblioteca pública. É torná-la parte integrante da comunidade.

Neste sentido, revisitar o conceito de biblioteca pública para o século XXI é uma necessidade para a compreensão da sua utilidade para a sociedade e com isso construir possibilidades de integração com o cidadão.

O caráter social e cultural da biblioteca pública contribui para a formação do seu potencial de intervenção nas dinâmicas sociais. Essa intervenção por sua vez atuará para a criação de relação íntima da biblioteca com seus usuários. Ao integrar-se com a comunidade a biblioteca estará construindo um território de atuação local.

Betancur (2007) entende que a construção social de um território local para as bibliotecas públicas é a interpretação da expressividade do cenário de identidades local e regional da comunidade usuária em prol da coletividade futura. Essa concepção é dada a partir dos processos de construção social da informação, do fomento à leitura e à cultura e se consolida pelo estímulo aos processos de participação da sociedade e das possibilidades de interação e transformação. Nessa perspectiva, para que a biblioteca pública se constitua como um território local de informação é preciso que seus serviços aproximem-se de maneira precisa e contundente da população usuária. É necessário, contudo, reconhecer a identidade da biblioteca pública, a globalização dos aspectos relacionados aos construtos local e global dessas possibilidades e, sobretudo, humanizar os serviços como requisito para uma aproximação entre a oferta e a demanda de informações.

Isto significa que é preciso antes de tudo, que a biblioteca pública e seus gestores conheçam a história dessa biblioteca, reconheçam suas condições históricas e principalmente, conheçam a sua comu- 
nidade e suas necessidades. É preciso o reconhecimento e a vinculação entre os atores sociais que envolvem a biblioteca, bibliotecário e usuário para a interação completa. É necessário também um planejamento das atividades no sentido local e regional, pensando as atividades de fora para dentro, ou seja, a partir das necessidades informacionais dos grupos de usuários e a adoção de estratégicas democráticas de participação da comunidade.

Quando pensamos em uma biblioteca que funciona nesse modelo, logo imaginamos que ela foi criada para esta comunidade específica e não foi fruto apenas da vontade de um governante de que ela fizesse parte da paisagem da cidade.

Neste sentido, Betancur (2007) aponta alguns desafios para a biblioteca pública se constituir em um território local de informação e cultura. São eles: rever a concepção de intervenção social a partir de bibliotecas; prestar serviços de informação local; compreender as relações entre informação e leitura; entender a biblioteca como um centro de encontro e intercambio de construção de múltiplas identidades; e participar do cenário e processos decisórios públicos da comunidade local. Este último é tão importante quanto conhecer a comunidade usuária e suas necessidades, pois situa a biblioteca em uma posição de integração social ativa e responsável para o desenvolvimento da comunidade a qual pertence.

Entretanto, para que isto possa se tornar realidade se faz necessária uma formação do bibliotecário, tanto com enfoque político quanto social para que possa desempenhar com responsabilidade e sabedoria esta função, conforme sintetiza Betancur (2007, p. 24):

\begin{abstract}
Os processos de construção de um território com contribuição substancial a partir das bibliotecas públicas implicam no reconhecimento das identidades culturais, a construção social da informação, projeto participativo dos serviços e avaliação coletiva para realmente conhecer $\circ$ impacto nas comunidades.
\end{abstract}

Um determinante para a construção de um território local de atuação para a biblioteca pública é a criação de redes de bibliotecas públicas funcionando como uma estratégia para o desenvolvimento de ações que viabilizem e oportunizem sua participação no processo decisório da comunidade em que está inserida. Outro fator é o conhecimento dos produtos e serviços e as transformações e trocas necessárias para que se efetive, de forma permanente, a criação de uso dos recursos de informação. Esse somatório contribui para a projeção da biblioteca pública na sociedade e dá maior visibilidade a instituição. Esse processo insere a biblioteca no panorama territorial da cidade e claro, institui uma nova concepção de biblioteca pública.

Brettas (2010, p. 102) pontua que uma nova concepção de biblioteca pública:

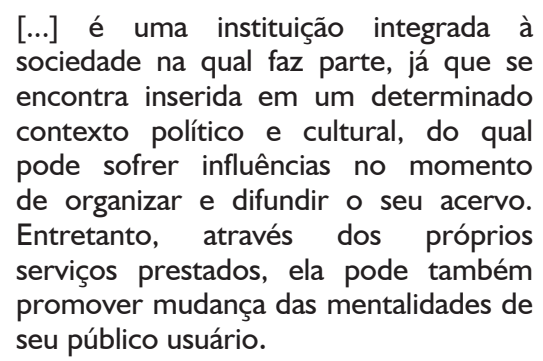

Para promover mudanças de mentalidade na comunidade a biblioteca precisa acima de tudo conhecer essa mentalidade. Essa percepção é responsável pela interação entre a biblioteca e a comunidade usuária e constitui as diferentes óticas que compõem a estética territorial de uma cidade. Conforme Betancur (2007), os cidadãos trazem em seu imaginário a representação dos diferentes contextos que abrigam a sua cidade.

Por sua vez, essa representação ajuda a construir um conceito de biblioteca pública integrada e com mobilidade cultural e visibilidade. Uma biblioteca pública que funcione como um centro de informações e que atue permanentemente atendendo às demandas informacionais da população e que seja da comunidade e para a comunidade.

\section{SISTEMA NACIONAL DE BIBLIOTECAS PÚBLICAS - SNBP/ RJ}

O Sistema Nacional de Bibliotecas Públicas (SNBP) foi criado pelo Decreto Presidencial $\mathrm{n}^{\circ}$ 520, de 13 de maio de $1992^{1}$, com o objetivo de contribuir para o fortalecimento das Bibliotecas Públicas do país.

O SNBP/RJ nasceu através de um projeto de implantação encaminhado por um Grupo

I VER: http://www.bn.br/snbp/historico.html 
de Trabalho da Associação dos Bibliotecários do Distrito Federal (ABDF) coordenado pelo Professor Antônio Agenor Briquet de Lemos. O projeto visava a implementação de recursos necessários à prestação de assistência técnica especializada às bibliotecas estaduais, com o objetivo de melhorar os serviços oferecidos e o estabelecimento de uma rede de colaboração mútua.

Neste sentido, o SNBP, com sede na Fundação Biblioteca Nacional (FBN/RJ), assume como pressuposto básico para o desenvolvimento de suas ações a função social da biblioteca pública como organização, entretanto, sem esquecer a sua função cultura e educadora. Sua atuação perante as demais bibliotecas públicas do país é possível pelo entendimento da biblioteca pública como sistema informacional, como uma unidade de informação sistêmica, voltada para as demandas informacionais da comunidade usuária e baseada em ações voltadas para a interação e integração dessas bibliotecas públicas em âmbito nacional.

\section{PROCEDIMENTOS METODOLÓGICOS}

Trata-se de uma pesquisa exploratória que conforme Gil (1999) tem como objetivo proporcionar uma maior familiaridade com o problema proposto a fim, de torná-lo explícito e construir hipóteses. Cervo, Bervian e Silva (2007) afirmam que a pesquisa exploratória ajuda a realizar descrições precisas da situação problema e a descobrir as relações existentes entre os elementos proponentes da investigação.

A investigação de natureza qualitativa é aquela que procura estabelecer um conceito bem definido daquilo que se estuda (GIBBS, 2009). O mapeamento das políticas públicas para bibliotecas públicas se baseou no Censo Nacional das Bibliotecas Municipais de 2010².

\section{ESTRATÉGIAS E POLÍTICAS PARA BIBLIOTECAS PÚBLICAS}

Políticas públicas são conjuntos de programas, projetos, ações e atividades desenvolvidas diretamente ou indiretamente pelo Estado e que podem ter a participação da sociedade civil.

\footnotetext{
2 VER: http://www.cenpec.org.br/biblioteca/educacao/estudos-epesquisas/censo-nacional-das-bibliotecas-publicas-municipais
}

As políticas públicas objetivam garantir o direito do cidadão, correspondendo a direitos assegurados constitucionalmente ou que se legitimam pelo reconhecimento da própria sociedade e pelo poder público. Essas políticas são formuladas principalmente por iniciativa do poder público a partir de demandas emanadas da sociedade. Faz-se necessário a participação da sociedade na formulação, no acompanhamento e na avaliação das propostas. Essa participação é garantida pela Lei Complementar $n^{\circ} 131$, de 27 de maio de 2009, estabelece,

I - incentivo à participação popular
e realização de audiências públicas,
durante os processos de elaboração e
discussão dos planos, lei de diretrizes
orçamentárias e orçamentos; II -
liberação ao pleno conhecimento
e acompanhamento da sociedade,
em tempo real, de informações
pormenorizadas sobre a execução
orçamentária e financeira, em meios
eletrônicos de acesso público (BRASIL,
2009, não paginado).

Neste sentido fica estabelecido que todos os poderes públicos em todas as esferas e níveis da administração pública estão obrigados a assegurar a participação da sociedade na formulação, implementação, acompanhamento, fiscalização e avaliação das políticas públicas.

Machado (2010, p. 97) afirma que as políticas públicas para bibliotecas públicas "são as políticas culturais que, por meio de sua administração pública e do conjunto de leis e regulamentações, buscam caminhos para o fortalecimento dessas bibliotecas e o estabelecimento de ações de longo alcance, com caráter permanente".

Ainda sobre as políticas públicas brasileiras para bibliotecas públicas, Lindoso (2004) aponta que a percepção sobre a importância das bibliotecas para a sociedade civil não surgiu espontaneamente da população, mas que foi um trabalho lento, de muito investimento e conscientização.

\section{I Algumas iniciativas brasileiras para bibliotecas públicas}

A criação do SNBP/RJ teve o objetivo de fortalecer as bibliotecas públicas através de um processo sistêmico baseado em ações de interação e integração das bibliotecas públicas do país. 
Entendemos que as políticas públicas para as bibliotecas em nível local compactuam para o estabelecimento de um território local de atuação para essas bibliotecas, uma vez que a biblioteca fará parte do panorama arquitetônico e cultural da cidade.

No Brasil, o Instituto Nacional do Livro (INL), criado em 1937 e extinto em 1990, foi o primeiro órgão governamental a promover e estabelecer políticas públicas para as bibliotecas públicas. O INL incentivou a abertura de bibliotecas públicas municipais e a formação de acervo para essas bibliotecas, através da edição de livros que eram distribuídos para cada município.

Após a extinção do INL o recém-criado SNBP tornou-se responsável pelas políticas públicas culturais para as bibliotecas e lança, em 2004, o Programa Livro Aberto com o objetivo de alcançar o êxito de ter uma biblioteca para cada município brasileiro.

Outra iniciativa voltada para a biblioteca e a formação de mediadores foi o Plano Nacional do Livro e da Leitura (PNLL), que trata-se de um conjunto de projetos, programas, atividades e eventos na área do livro, da leitura, da literatura e de bibliotecas em desenvolvimento.

O projeto Uma biblioteca em cada Município, concebido e implementado pelo MinC no período de 1995 a 2002, objetivou ampliar o acesso ao livro através da abertura e revitalização de bibliotecas públicas por todo o Brasil mediante convênio com municípios.

Em 2005 foi lançado o programa Fome de Livro que, entre outras coisas, prevê a continuidade do projeto Uma Biblioteca em cada Município com abertura de bibliotecas através de convênios com municípios. Sobre a iniciativa Machado (2010, p. 102) afirma que o programa "surge como uma estratégia para articular o conjunto de ações realizadas pelo Estado, pelas empresas e pela sociedade civil organizada".

Em 2011 a FBN através do SNBP lançou o Cadastro Nacional de Bibliotecas em conjunto com o Sistema Nacional de Informação e Indicadores Culturais (SNIIC). O cadastro tinha o objetivo de mapear de forma abrangente todas as bibliotecas existentes no país, sejam elas públicas, comunitárias, escolares, universitárias, ou especializadas, levantando dados sobre a relação institucional, público, acervo, serviços, infraestrutura e gestão. $\mathrm{O}$ cadastro era requisito para a participação das bibliotecas em programas de modernização e atualização de acervos.
O projeto Arca das Letras, lançado em 2003 pelo Ministério da Reforma Agrária, por meio da Secretaria do Desenvolvimento Agrário, tinha o objetivo de criar bibliotecas rurais e formar agentes de leitura locais para atuar nesses espaços.

Para complementar o Arca das Letras, foi criado em 2006 o projeto Bibliotecas Famílias Agrícolas, focando na distribuição de livros para as escolas, famílias agrícolas e casas familiares rurais.

\subsection{Mapeamento da situação das bibliotecas brasileiras públicas municipais}

Do universo dos 5.565 municípios brasileiros 4.763 bibliotecas públicas municipais estão em funcionamento, fase de implantação ou modernização. O censo aponta para um resultado positivo no que diz respeito ao período de funcionamento. Das bibliotecas públicas mapeadas, $99 \%$ funcionam de segunda a sextafeira no período da manhã e da tarde.

Gráfico 1 - Bibliotecas públicas por regiões brasileiras

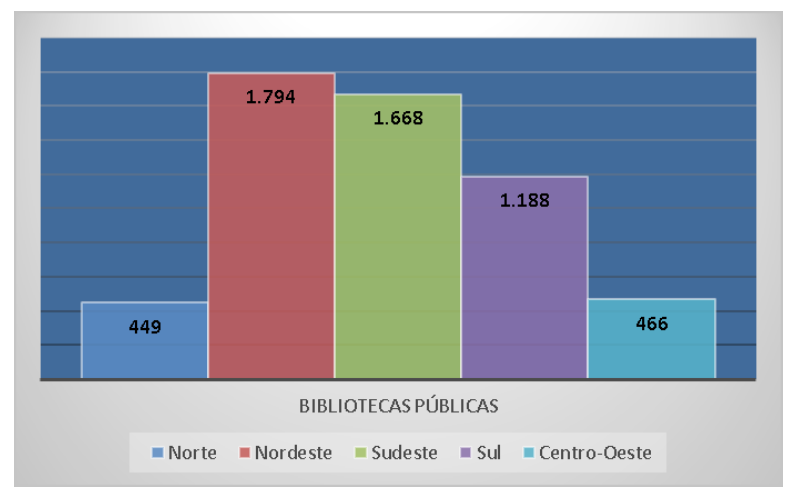

Fonte: A autora baseada nos dados do IBGE, (2012).

A região nordeste concentra o maior número de bibliotecas públicas, entretanto é proporcionalmente menor em número de municípios se comparada com a região sudeste. Desse total o Censo (2010) aponta que 79\% dessas bibliotecas estão em funcionamento, conforme pode-se observar no gráfico abaixo. Esta questão é importante, pois cria um relacionamento entre a biblioteca e a cidade, cria uma relação de pertencimento à comunidade. 
Gráfico 2 - Bibliotecas Públicas Municipais em Funcionamento ou em Fase de Implantação

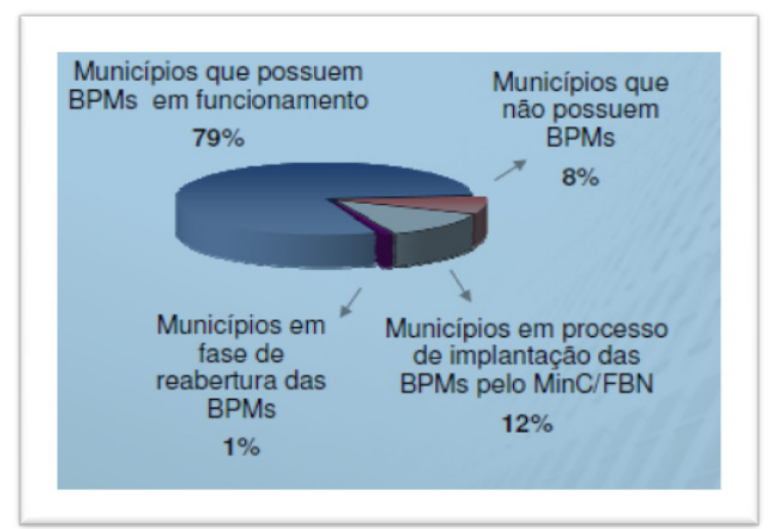

Fonte: CENSO (2010).

Com relação a atuação das bibliotecas públicas brasileiras, 91\% não possuem serviços direcionados a pessoas com deficiência visual e $94 \%$ não oferecem serviços para pessoas com demais necessidades especiais. E $88 \%$ não têm nenhum tipo de atividade de extensão. Essa realidade afasta a biblioteca de sua comunidade e do estabelecimento de um território local de atuação. São as ações que se dão pela e com a comunidade que fortalecem a criação e manutenção de um sentimento de pertencimento à clientela. $\mathrm{O}$ fato das bibliotecas públicas brasileiras não construírem relacionamento direto com sua comunidade atua de forma inversa quanto a construção de um estado de pertencimento à biblioteca.

Gráfico 3 - Estrutura Física das Bibliotecas Públicas Municipais

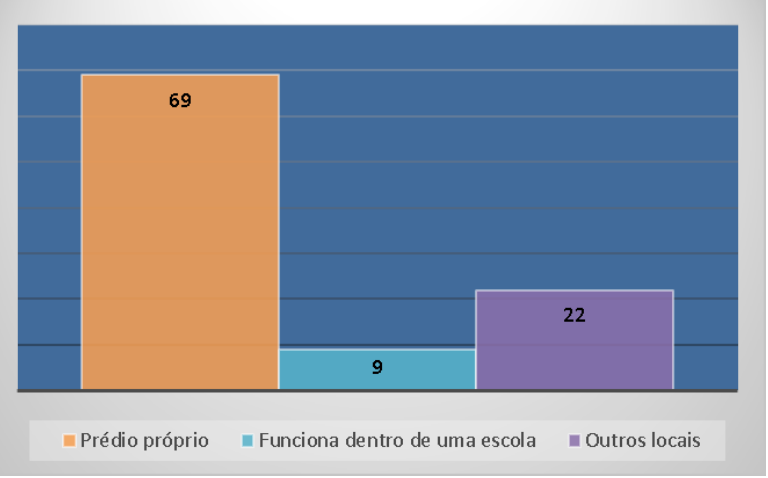

Fonte: CENSO (2010).

Os serviços oferecidos também são responsáveis pela visibilidade da biblioteca pública, uma vez que cria rotinas e ajuda a formação de público. Entretanto, infelizmente poucas são as bibliotecas brasileiras que oferecem serviços diferenciados para usuários com necessidades específicas.

Gráfico 4 - Equipamentos e Serviços Oferecidos pelas Bibliotecas Públicas Municipais

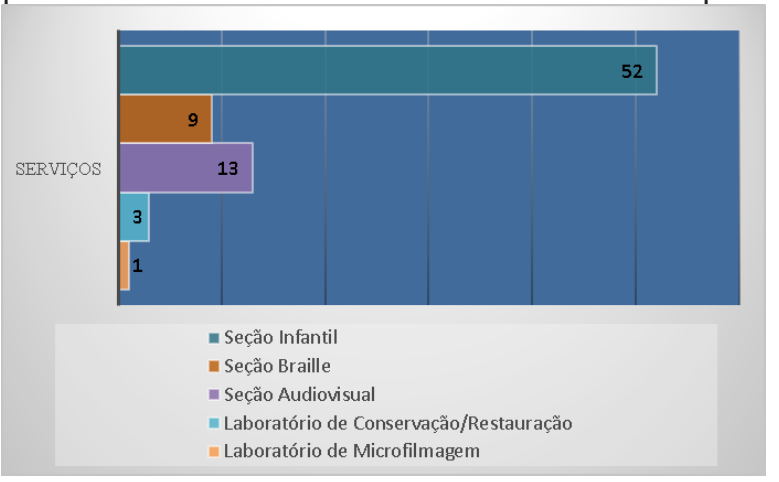

Fonte: CENSO (2010).

As atividades culturais podem criar vínculos entre o espaço e o usuário, constituir a efetivação da compreensão de identidade para a biblioteca e criar possibilidades de território local para as bibliotecas públicas.

O setor infantil é responsável por $52 \%$ dos equipamentos e serviços oferecidos, seguido pelo setor audiovisual com 13\%. Apesar de contemplar um setor de audiovisual faltam às bibliotecas públicas municipais um espaço para atividades culturais que possibilitem a integração da biblioteca, seus serviços e a comunidade usuária. Esse espaço, dependendo do tipo de atividade oferecida, pode ser substituído pelo setor de audiovisual, entretanto, é preciso que haja uma interação entre o serviço oferecido e as necessidades dos cidadãos.

Gráfico 5 - Acesso à internet

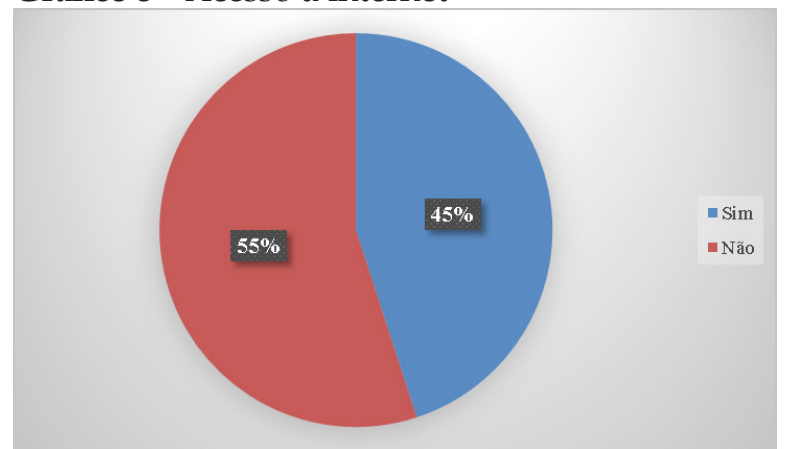

Fonte: CENSO (2010). 
Abrigada na sociedade da informação, a biblioteca pública precisa aliar-se à internet e às tecnologias para atender de forma satisfatória as necessidades informacionais da comunidade usuária.

Do total de bibliotecas em funcionamento $55 \%$ não possuem acesso à internet, conforme visualizamos no Gráfico 5. Este resultado coloca a biblioteca em desequilíbrio com as necessidades modernas de informação da sociedade. Analisando este quesito por regiões, temos os piores resultados para a região norte com $20 \%$ e a região nordeste com $28 \%$ das bibliotecas municipais com acesso à internet.

Outro fator relevante para o estabelecimento de possibilidades de construção social de um território local de atuação para as bibliotecas públicas é o percentual de bibliotecas que oferecem o serviço de internet à clientela, conforme podemos observar no próximo gráfico.

Gráfico 6 - Bibliotecas Que Oferecem Acesso à Internet à Clientela

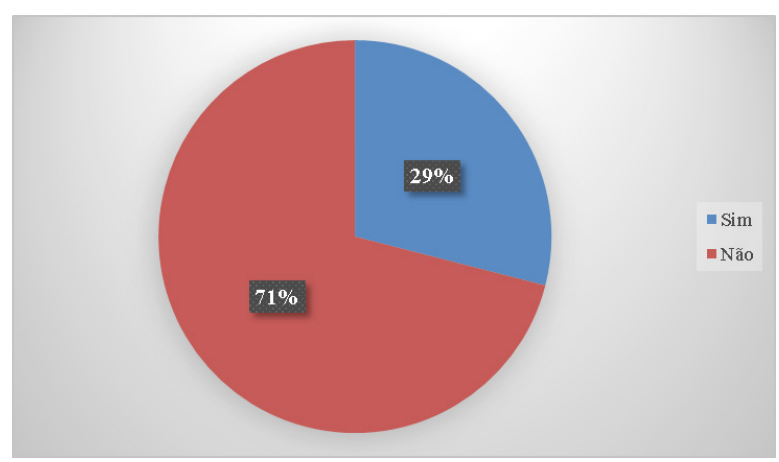

Fonte: CENSO (2010).

Apenas 29\% das bibliotecas municipais oferecem o serviço de internet a sua clientela. Déficit ainda maior é verificado nas regiões norte e nordeste com 15\% e 18\% respectivamente de bibliotecas públicas que disponibilizam internet aos usuários. Entretanto, é um resultado previsível devido aos incentivos das políticas direcionadas para a região sul e sudeste.
Gráfico 7- Serviços Oferecidos Pelas Bibliotecas

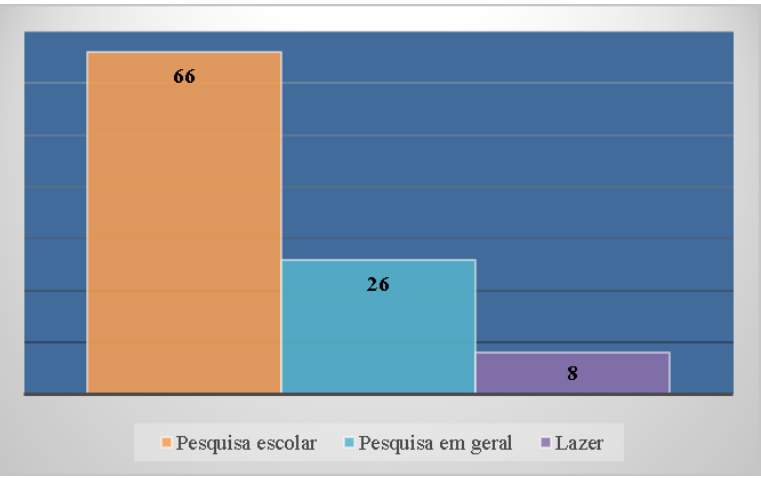

Fonte: CENSO (2010).

Os serviços oferecidos evidenciam uma atuação junto a comunidade escolar com que repete discursos da escolarização dos serviços da biblioteca pública. Essa é uma característica que remonta aos anos 1970 que transformaram as bibliotecas públicas em verdadeiras bibliotecas escolares, uma vez em que essas bibliotecas assumiam a função de atendimento aos estudantes (BERNARDINO; SUAIDEN, 2011).

Gráfico 8 - Programação Cultural Oferecida Regularmente Pelas Bibliotecas

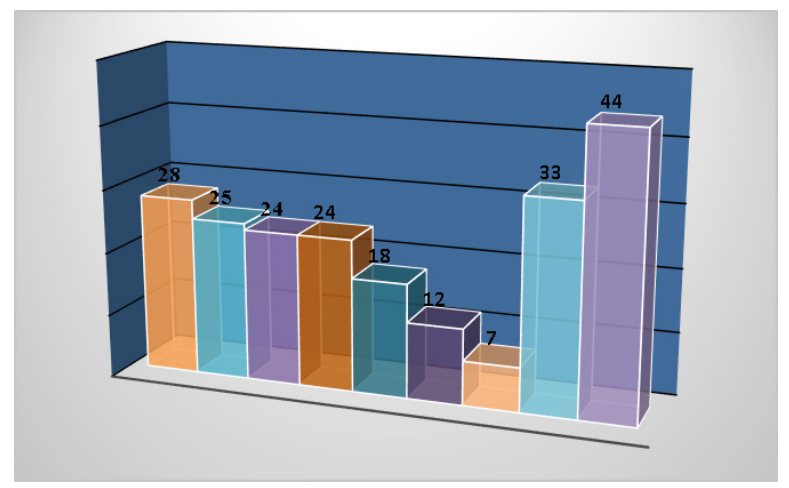

Fonte: CENSO (2010).

O Gráfico 8 demonstra que $65 \%$ das bibliotecas públicas brasileiras centram seus serviços na pesquisa escolar e apenas 8\% oferecem atividades de lazer aos usuários. O próximo gráfico traz um resultado de $44 \%$ de bibliotecas municipais que não oferecem nenhuma programação cultural para a clientela.

Outra observação é a preocupação com as atividades de leitura na biblioteca pública como oficinas e rodas de leitura, saraus literários, atividades de mediação da leitura e agentes de leitura. 


\section{CONSIDERAÇÕES FINAIS}

Entendemos que a função da biblioteca pública de garantir o acesso a informação em qualquer suporte ou formato é um aspecto fundamental para o desenvolvimento da cultura e da educação e tem caráter democrático e social.

A biblioteca pública conforme orienta Suaiden (1995) deve utilizar metodologias para auxiliar no diagnóstico das necessidades de informação da comunidade. Este é o primeiro passo para a instituição de um território local de atuação para a biblioteca pública. Ainda segundo $\mathrm{o}$ autor, as bases da comunidade são localidade e consciência de si mesma, sendo uma área dotada de vida e de certo grau de coesão.

Este forte sentimento de localização é a condição necessária para criar a comunidade e é também a condição que conecta a biblioteca, mais especificamente, a biblioteca pública no panorama territorial de cada cidade. É esse pertencimento que institui e implementa a biblioteca pública como território local e a legitimação se dá pela sua atuação na comunidade.
A criação de rotinas de atividades culturais compactua para a construção social de um território local de atuação para a biblioteca pública, pois a interação da biblioteca com o panorama arquitetônico e cultural do município garantirá um maior relacionamento entre a biblioteca e a sua clientela.

Esse relacionamento e a sensação de pertencimento será responsável pela intrínseca interação dos cidadãos e a biblioteca, construindo um território local legitimado socialmente.

A participação da sociedade é imprescindível nesse processo. E a instituição de políticas para a biblioteca pública que funcione de forma integrada com o interesse da sociedade é fundamental. É preciso, conforme orienta Machado (2010) que essas políticas respeitem processos e etapas, tenha clareza e objetividade e principalmente, respeitem a participação democrática dos cidadãos. A biblioteca pública como espaço democrático e território local passa pela distribuição social e justa de informação e o que ajuda a construir são as políticas culturais.

Artigo recebido em 17/10/2016 e aceito para publicação em 18/02/2017

\section{POLICIES FOR CONSTRUCTION OF TERRITORY OF PRACTICE FOR LOCAL PUBLIC LIBRARY}

ABSTRACT Public libraries assume large challenges in society, particularly the development of information systems and responsibilities towards the information society. The social construction of a local territory for public libraries is an interpretation of expressiveness scenario identities of local and regional user community in supporting the community. The aim of this paper is to discuss the role of the National System of Public Libraries - SNBP / RJ for the social construction of territory development site for information and knowledge from the public libraries. Exploratory research provides an overview of the fact and qualitative analysis contributes to the development of social constructs guiding policies for public libraries. To listing the radius of operation and management aspects of public policies in Brazil, results are indicated as a mapping local and global role of public libraries SNBP / RJ, contributing to the socio-political projection of public libraries and their undeniable contribution to local development. We understand that the role of the public library to ensure access to information in any medium or format is a key aspect for the development of culture and education and has a democratic and social. Finally, we present the contributions of the public library to promote human from the recognition of local realities, integrating cultures and promoting the empowerment of individuals and groups, thereby promoting the economic and social development of the community.

Keywords: $\quad$ Public Library. Local Territory. Social Development; Information Society; Library. 


\section{REFERÊNCIAS}

BERNARDINO, M. C. R.; SUAIDEN, E. J. Concepção de imagem pública das bibliotecas polos do Estado do Ceará. Inf. \& Soc.: estudos, v. 21, n. 2, p. 25-34, maio./ago., 2011. Disponível em: <http://www.ies.ufpb.br/ojs2/index.php/ ies/article/view/9824/5960 >. cesso em: 12 abr. 2016.

BETANCUR, A. M. B. Bibliotecas públicas, información y desarrollo local. Medellín: Comfenalco Antioquia, 2007.

BRASIL. Presidência da República. Casa Civil. Lei Complementar no 131, de 27 de maio de 2009. Estabelece normas de finanças públicas voltadas para a responsabilidade na gestão fiscal. Diário Oficial [da] República Federativa do Brasil, Poder Executivo, Brasília, DF, Disponível em:< http://www.planalto.gov.br/ccivil_03/leis/lcp/ lcp131.htm >.Acesso em: 10 abr. 2016.

BRETTAS, A. P. A biblioteca pública: um papel determinado e determinante na sociedade. Biblos, v. 24, n. 2, p. 101-118, jul./dez., 2010. Disponível em: <http://www.seer.furg.br/ biblos/article/download/1153/1030\% 20\% 20 \%E2\%80\%8E>. Acesso em: 10 abr. 2016.

CENSO NACIONAL DE BIBLIOTECAS PÚBLICAS: estudo quantitativo, principais resultados. Rio de Janeiro: Fundação Biblioteca Nacional / Fundação Getúlio Vargas. 2010. Disponível em:< http://www.cenpec.org.br/ biblioteca/educacao/estudos-e-pesquisas/censonacional-das-bibliotecas-publicas-municipais >. Acesso em: 12 abr. 2016.

CERVO, A. L.; BERVIAN, P. A.; SILVA, R. Metodologia científica. 6. ed. São Paulo: Pearson Prentice Hall, 2007.

GIBBS, G. Análise de dados qualitativos. Porto Alegre: Artmed, 2009.

GIL, A. C. Como elaborar projetos de pesquisa. 4. ed. São Paulo: Atlas, 1999.

IBGE. Perfil dos municipios brasileiros: quantitativo de bibliotecas nos municipios brasileiros. 2012. Disponível em:< ftp://ftp.ibge.
gov.br/Perfil_Municipios/2012/pdf/tab026.pdf >.Acesso em: 12 abr. 2016.

JARAMILLO, O.; MONTOYA RÍOS, M. Revisión del concepto de biblioteca pública. In: JARAMILLO, O.; MONTOYA RÍOS, M.; ÁLVAREZ ZAPATA, D. (Eds.). Biblioteca pública y lectura pública. Medellín: Universidad de Antioquia, Escuela Interamericana de Bibliotecología, 2005.

LINDOSO, F. O Brasil pode ser um país de leitores?: política para a cultura/política para o livro. São Paulo: Summus, 2004.

LOZANO DÍAZ, R. La biblioteca pública Del siglo XXI: atendiendo clientes, movilizando personas. Gijon, Asturias: Ediciones Trea S. L., 2006.

MACHADO, E. C. Análise de políticas públicas para bibliotecas no Brasil. InCID Rev. Ci. Inf. Doc., Ribeirão Preto, v. 1, n. 1, p. 94-111, jan./ jun., 2010. Disponível em: http://www.revistas. usp.br/incid/article/view/42307/45978 Acesso em: 11 abr. 2016.

PINHEIRO, R. Q. Biblioteca pública: seu lugar na cidade. CRB-8 Digital, v. 2, n. 1, p. 27-29, maio., 2009. Disponível em: <http://revista. crb8.org.br/index.php/crb8digital/article/ viewFile/13/13>. Acesso em: 9 abr. 2016.

SUAIDEN, E. J. Biblioteca pública e informação à comunidade. São Paulo: Global, 1995. 